\title{
Enhancement of USM3D Unstructured Flow Solver for High-Speed High-Temperature Shear Flows
}

\author{
Mohagna J. Pandya* \\ Analytical Services \& Materials, Inc, Hampton, Virginia 23666 \\ Khaled S. Abdol-Hamid ${ }^{\dagger}$ and Neal T. Frink ${ }^{*}$ \\ NASA Langley Research Center, Hampton, Virginia 23681
}

\begin{abstract}
Large temperature and pressure fluctuations have a profound effect on turbulence development in transonic and supersonic jets. For high-speed, hightemperature jet flows, standard turbulence models lack the ability to predict the observed mixing rate of a shear layer. Several proposals to address this deficiency have been advanced in the literature to modify the turbulence transport equations in a variety of ways. In the present study, some of the most proven and simple modifications to two-equation turbulence models have been selected and implemented in NASA's USM3D tetrahedral Navier-Stokes flow solver. The modifications include the addition of compressibility correction and pressure dilatation terms in the turbulence transport equations for high-speed flows, and the addition of a simple modification to the Boussinesq's closure model coefficient for high-temperature jets. The efficacy of the extended models is demonstrated by comparison with experimental data for two supersonic axisymmetric jet test cases at design pressure ratio.
\end{abstract}

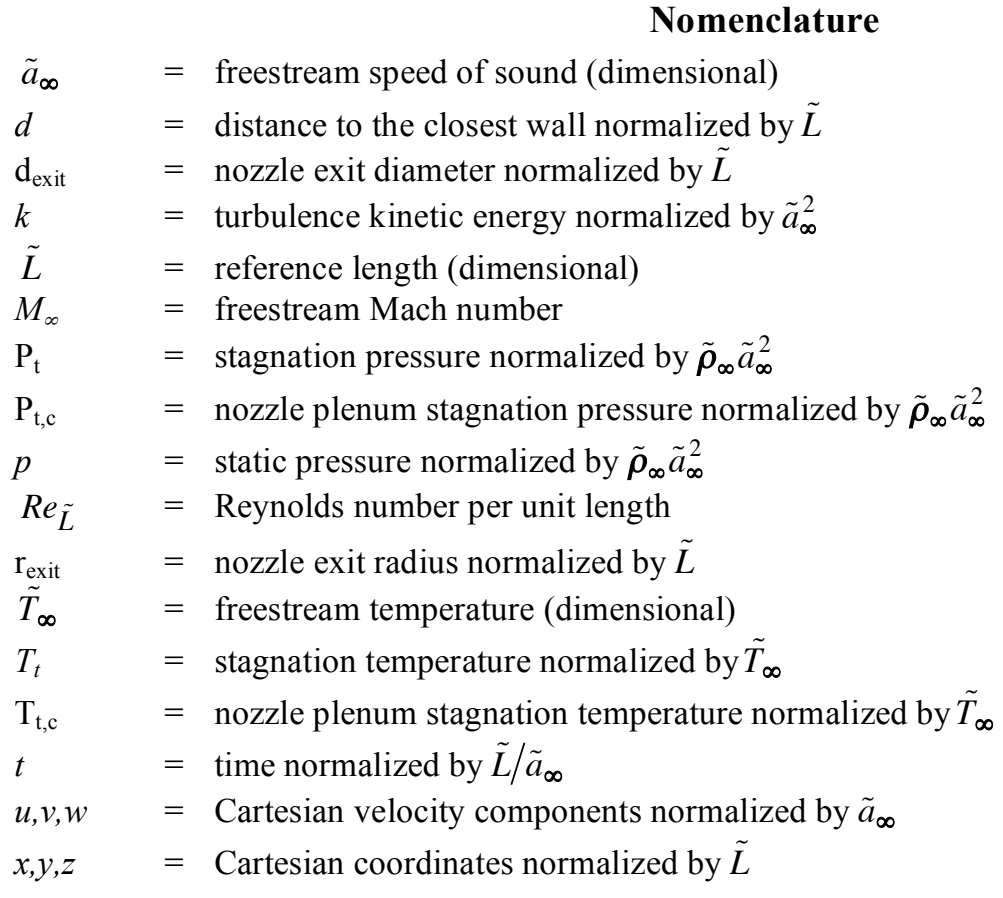

\footnotetext{
* Senior Scientist, Mail Stop 499, NASA Langley Research Center, Senior Member AIAA.

$\dagger$ Senior Research Engineer, Configuration Aerodynamics Branch, Mail Stop 499, Associate Fellow AIAA.

* Senior Research Engineer, Configuration Aerodynamics Branch, Mail Stop 499, Associate Fellow AIAA.
} 


$\begin{array}{ll}\varepsilon & =\text { turbulence dissipation normalized by } \tilde{a}_{\infty}^{4} / \tilde{\boldsymbol{v}}_{l_{\infty}} \\ \tilde{\boldsymbol{v}}_{l_{\infty}} & =\text { freestream laminar kinematic viscosity (dimensional) } \\ \boldsymbol{v}_{l} & =\text { laminar kinematic viscosity normalized by } \tilde{\boldsymbol{v}}_{l_{\infty}} \\ \boldsymbol{v}_{t} & =\text { eddy viscosity normalized by } \tilde{\boldsymbol{v}}_{l_{\infty}} \\ \hat{\boldsymbol{v}} & =\text { primary unknown in Spalart-Allmaras turbulence model, normalized by } \tilde{\boldsymbol{v}}_{l_{\infty}} \\ \tilde{\boldsymbol{\rho}}_{\infty} & =\text { freestream density (dimensional) } \\ \rho & =\text { density normalized by } \tilde{\boldsymbol{\rho}}_{\infty} \\ \boldsymbol{\rho} e_{0} & =\text { stagnation energy per unit volume normalized by } \tilde{\boldsymbol{\rho}}_{\infty} \tilde{a}_{\infty}^{2} \\ \omega & =\text { turbulence specific dissipation rate normalized by } \tilde{a}_{\infty}^{2} / \tilde{\boldsymbol{v}}_{l_{\infty}}\end{array}$

\section{Introduction}

$\mathrm{T}$ HE NASA Constellation program is relying heavily on Computational Fluid Dynamic (CFD) tools to complement ground-based wind tunnel testing to aid the design and aerodynamic database development for the ARES I Crew Launch Vehicle (CLV), Orion Crew Exploration Vehicle (CEV) and Launch Abort Vehicle (LAV). These next-generation space vehicles are currently under development to replace the Space Shuttle in the next decade.

The ARES-series of launch vehicles utilize large numbers of control jets during ascent and stage separations to maintain stable flight. These control jets operate in close proximity to aerodynamic surfaces at very high temperatures and over a wide range of Mach numbers, from subsonic to supersonic. Similarly, powerful Abort Motor jets and smaller Abort Control Motor jets will dominate the aerodynamic characteristics of the LAV during a launch abort, should such an unfortunate emergency occur. As might be expected, maintaining accurate simulation of jet-dominated aerodynamics on these vehicles is a formidable task. Considerable effort is being expended to develop suitable experimental techniques and numerical models for simulating these flows. The TetrUSS USM3D flow solver [1] serves as the lead CFD tool within the ARES program to develop the computational aerodynamic database and loads for the vehicle up through supersonic speeds. The USM3D solver is also lending critical support to the aerodynamic development of the CEV and LAV vehicles.

This paper focuses on the extension of the advanced numerical turbulence models within the USM3D Navier-Stokes flow solver to improve the simulation accuracy for jet-dominated flows. Within such flows, large temperature and pressure fluctuations have a profound effect on the development of turbulence for transonic and supersonic jets. For high-speed, high-temperature jet flows, standard turbulence models lack the ability to predict the observed mixing rate of a shear layer. Several proposals to address this deficiency have been advanced in the literature to modify the turbulence transport equations in a variety of ways. Some of the most proven and simple modifications to two-equation turbulence models have been selected and implemented in the USM3D flow solver. The modifications include the addition of compressibility correction and pressure dilatation terms in the turbulence transport equations for high-speed flows, and the addition of a simple modification to the Boussinesq's closure model coefficient for high-temperature jets. The efficacy of the extensions is demonstrated by comparison with experimental data for two supersonic axisymmetric jet test cases at design pressure ratio. The new turbulence modeling capability is currently in heavy use within the NASA Constellation program following an extensive study on the Orion LAV with Abort Motors to determine which turbulence models best correlate with subsonic/transonic wind-tunnel data.

\section{Description of Methodology}

The NASA Tetrahedral Unstructured Software System (TetrUSS) [1] is a complete flow analysis system that has been widely used in industry and government since 1991. Its strength is derived from harnessing various component technologies into a user-friendly system to provide rapid, higher-order analysis and design capability to the applied aerodynamicists. The system consists of loosely integrated, user-friendly software that comprises a geometry setup utility GridTool [2], a tetrahedral grid generator VGRID [3], [4], a flow solver USM3D [5], [6], and post-processing visualization and data extraction utilities. The extensions addressed in this paper pertain to the USM3D flow solver, and will be described below. 


\section{A. USM3D Flow Solver}

USM3D is a tetrahedral cell-centered, finite volume Euler and Navier-Stokes (N-S) flow solver. Inviscid flux quantities are computed across each cell face using Roe's [7] flux-difference splitting (FDS), Liou's [8] Advection Upstream Splitting Method (AUSM+) or Toro's HLLC scheme [9]. Spatial discretization is accomplished by a novel reconstruction process [10], based on an analytical formulation for computing solution gradients within tetrahedral cells. The solution is advanced to a steady-state condition by an implicit backward-Euler time-stepping scheme [11].

USM3D has several closure models for capturing flow turbulence effects. First is the Spalart-Allmaras (SA) one-equation model [12], which can be coupled with a wall function boundary condition to reduce the number of cells in the sublayer region of the boundary layer. However, the wall function is typically used only when extensive curvature-based separation is not expected in a flow simulation. The second model is the two-equation $k-\varepsilon$ turbulence model [13]. The third model is the Menter SST two-equation model [14]. These turbulence models have undergone rigorous testing on propulsion afterbody flows in Ref. [15]. In addition, nonlinear Algebraic Reynolds Stress Models (ARSM) of Shih et al. [16] and Girimaji [17] have also been incorporated in USM3D. The two algebraic Reynolds stress models give inherently better results than the linear stress model because of the explicit modeling of effects such as relaxation, and the specific inclusion of nonlinear anisotropic effects from the mean flow strain and vorticity. With a nonlinear model, the calculation of six independent, realizable Reynolds stress terms is possible. This type of detail is important for simulating complicated multidimensional flows. A capability to trip the flow at specified locations on aerodynamic surfaces has been implemented for the $k-\varepsilon$ turbulence model [18].

USM3D supports an array of useful boundary conditions (BCs). It contains the standard BCs of flow tangency or no-slip on solid surfaces, characteristic inflow/outflow for subsonic boundaries, and freestream inflow and extrapolation outflow for supersonic flow. It also contains some additional special BCs for jet exhaust and intake, a propeller/rotor actuator disk model, and passive porosity [19]. The most recent enhancements to USM3D are second-order time accuracy, Detached Eddy Simulation (DES) capability, dynamic grid motion [20], and overset-grid moving body capability [21].

The USM3D runs on massively parallel computers and clusters of personal computers. A gridpartitioning file is quickly generated during the preprocessing step. A global restart file is generated and saved during and after each run.

\section{B. Turbulence Model Enhancements}

The two-equation $k-\varepsilon$ and SST turbulence models have been modified for jet flow computations to improve the prediction of jet spreading rates. Compressibility correction formulations of Sarkar [22], and Wilcox [23], and pressure dilatation terms have been added to both two-equation models following the approach of Suzen and Hoffman [24]. In addition, a simple modification to the Boussinesq's closure model coefficient has been implemented in the $k$ - $\varepsilon$ turbulence model for high-temperature jets [25].

\section{Mean Flow Governing Equations}

Reynolds Averaged Navier-Stokes (RANS) equations are the governing equations solved in this study. The perfect gas law is chosen to represent air properties. The mass, momentum, and energy conservation equations in the time-averaged conservative simplified form can be written as follows:

$$
\begin{aligned}
& \frac{\partial \rho}{\partial t}+\frac{\partial \rho u_{i}}{\partial x_{i}}=0 \\
& \frac{\partial \rho u_{i}}{\partial t}+\frac{\partial\left(\rho u_{i} u_{j}+p \delta_{i j}\right)}{\partial x_{j}}=\frac{\partial\left(\boldsymbol{\tau}_{i j}-\rho \overline{u_{i} u_{j}}\right)}{\partial x_{j}} \\
& \frac{\partial \rho e_{0}}{\partial t}+\frac{\partial\left(\rho e_{0} u_{i}+p u_{i}\right)}{\partial x_{i}}=\frac{\partial\left(\boldsymbol{\tau}_{i j} u_{j}-\rho \overline{u_{i} u_{j}} u_{j}\right)}{\partial x_{i}}-\frac{M_{\infty}}{\operatorname{Re}_{\tilde{L}}} \frac{\partial}{\partial x_{i}}\left[\frac{-1}{\gamma-1} \rho\left(\frac{\boldsymbol{v}_{l}}{\operatorname{Pr}}+\frac{\boldsymbol{v}_{t}}{\operatorname{Pr}_{t}}\right) \frac{\partial T}{\partial x_{i}}\right]+\frac{M_{\infty}}{\operatorname{Re}_{\tilde{L}}} \frac{\partial}{\partial x_{i}}\left[\rho\left(\boldsymbol{v}_{l}+\frac{\boldsymbol{v}_{t}}{\sigma_{k}}\right) \frac{\partial k}{\partial x_{i}}\right]
\end{aligned}
$$

In the above equations, $\delta_{i j}$ is Kronecker delta, $\tau_{i j}$ is the laminar shear stress, and $\gamma$ is the ratio of specific heats. The term $\overline{u_{i} u_{j}}$ is the turbulent shear stress, which will be defined later. 


$$
\boldsymbol{\tau}_{i j}=\frac{M_{\infty}}{\operatorname{Re}_{\tilde{L}}} 2 \rho v_{l} S_{i j}, \quad S_{i j}=\frac{1}{2}\left[\frac{\partial u_{i}}{\partial x_{j}}+\frac{\partial u_{j}}{\partial x_{i}}\right]-\frac{1}{3} \boldsymbol{\delta}_{i j} \frac{\partial u_{i}}{\partial x_{j}}
$$

Three turbulence models are used in the current study: the standard SA model [12], linear $k-\varepsilon$ model [13] enhanced with compressibility corrections, pressure dilatation term and temperature correction as well as Menter SST model [14] enhanced with compressibility corrections and pressure dilatation term. The eddy-viscosity concept is used to model the Reynolds stresses. The algebraic Reynolds stress models of Shih-Zhu-Lumley (SZL) [16] and Girimaji [17] have been found to be the most beneficial, primarily in wall-bounded flows. Past applications of these models for jet flows using PAB3D code [25] have yielded unsteady solutions, and therefore these models have not been used in the current studies based on the $k-\varepsilon$ model. The standard SA model is included for reference, since it is a widely used turbulence model for computational applications. The governing equations for the three turbulence models are presented below.

\section{Standard SA Model}

$$
\begin{gathered}
\frac{\partial \hat{\boldsymbol{v}}}{\partial t}+u_{i} \frac{\partial \hat{\boldsymbol{v}}}{\partial x_{i}}=C_{b_{1}}\left[1-f_{t_{2}}\right] \hat{S} \hat{\boldsymbol{v}}-\frac{M_{\infty}}{\operatorname{Re}_{\tilde{L}}}\left[C_{w_{1}} f_{w}-\frac{C_{b_{1}}}{\boldsymbol{\kappa}^{2}} f_{t_{2}}\right]\left(\frac{\hat{\boldsymbol{v}}}{d}\right)^{2}-\frac{M_{\infty}}{\operatorname{Re}_{\tilde{L}}} \frac{C_{b_{2}}}{\sigma} \hat{\boldsymbol{v}} \frac{\partial^{2} \hat{\boldsymbol{v}}}{\partial x_{i}^{2}}+\frac{M_{\infty}}{\operatorname{Re}_{\tilde{L}}} \frac{1}{\sigma} \frac{\partial}{\partial x_{i}}\left[\left(\boldsymbol{v}_{l}+\left(1+C_{b_{2}}\right) \hat{\boldsymbol{v}}\right) \frac{\partial \hat{\boldsymbol{v}}}{\partial x_{i}}\right] \\
v_{t}=\hat{\boldsymbol{v}}_{v_{1}}, \quad f_{v_{1}}=\frac{\chi^{3}}{\chi^{3}+C_{v_{1}}^{3}}, \quad \chi=\frac{\hat{\boldsymbol{v}}}{\boldsymbol{v}_{l}} \\
\qquad f_{t_{2}}=C_{t_{3}} \exp \left(-C_{t_{4}} \chi^{2}\right) \\
\hat{S}=\boldsymbol{\Omega}+\frac{M_{\infty}}{\operatorname{Re}_{\tilde{L}}} \frac{\hat{\boldsymbol{v}}}{\boldsymbol{\kappa}^{2} d^{2}} f_{v_{2}}, \quad f_{v_{2}}=1-\frac{\chi}{1+\chi f_{v_{1}}}, \quad \Omega \text { is the vorticity magnitude. } \\
f_{w}=g\left[\frac{1+C_{w_{3}}^{6}}{g^{6}+C_{w_{3}}^{6}}\right]^{1 / 6}, \quad g=r+C_{w_{2}}\left(r^{6}-r\right), \quad r=\frac{M_{\infty}}{\operatorname{Re}_{\tilde{L}}} \frac{\hat{\boldsymbol{v}}}{\hat{S} \boldsymbol{\kappa}^{2} d^{2}}, \quad r=\min (r, 20)
\end{gathered}
$$

As seen from the equations above, the trip term is not included in the USM3D implementation of the SA model. The constants used in the above model are defined below.

$$
\begin{gathered}
C_{b_{1}}=0.1355, \quad C_{b_{2}}=0.622, \quad \sigma=2 / 3, \quad \kappa=0.41, \quad C_{w_{1}}=C_{b_{1}} / \kappa^{2}+\left(1+C_{b_{2}}\right) / \sigma \\
C_{w_{2}}=0.3, \quad C_{w_{3}}=2, \quad C_{v_{1}}=7.1, \quad C_{t_{3}}=1.1, \quad C_{t_{4}}=2
\end{gathered}
$$

$\hat{\boldsymbol{v}}_{\text {wall }}=0$ is applied for the sub-layer resolving grid. The SA model can also be optionally coupled with the wall function formulation inside USM3D [6]. 
3. $k$ - $\varepsilon$ Model

$$
\begin{gathered}
\frac{\partial \rho k}{\partial t}+\frac{\partial \rho u_{i} k}{\partial x_{i}}=-\rho \overline{u_{i} u_{j}} \frac{\partial u_{j}}{\partial x_{i}}+\frac{M_{\infty}}{\operatorname{Re}_{\tilde{L}}} \frac{\partial}{\partial x_{i}}\left[\rho\left(\boldsymbol{v}_{l}+\frac{c_{\mu} k^{2}}{\sigma_{k} \varepsilon}\right) \frac{\partial k}{\partial x_{i}}\right]-\frac{\operatorname{Re}_{\tilde{L}}}{M_{\infty}} \boldsymbol{\rho} \boldsymbol{\varepsilon}(1+\Gamma)+P D \\
\frac{\partial \rho \varepsilon}{\partial t}+\frac{\partial \rho u_{i} \varepsilon}{\partial x_{i}}=-C_{\varepsilon 1} \rho \overline{u_{i} u_{j}} \frac{\partial u_{j}}{\partial x_{i}} \frac{\varepsilon}{k}+\frac{M_{\infty}}{\operatorname{Re}_{\tilde{L}}} \frac{\partial}{\partial x_{i}}\left[\rho\left(\boldsymbol{v}_{l}+\frac{c_{\mu} k^{2}}{\sigma_{\varepsilon} \varepsilon}\right) \frac{\partial \varepsilon}{\partial x_{i}}\right]-f_{2} C_{\varepsilon 2} \rho \frac{\varepsilon}{k}\left[\frac{\operatorname{Re}_{\tilde{L}}}{M_{\infty}} \varepsilon-2 \frac{M_{\infty}}{\operatorname{Re}_{\tilde{L}}} \boldsymbol{v}_{l}\left(\frac{\partial \sqrt{k}}{\partial x_{i}}\right)^{2}\right] \\
C_{\varepsilon 1}=1.44, \quad C_{\varepsilon 2}=1.92, \quad \sigma_{k}=1.0, \quad \sigma_{\varepsilon}=1.3
\end{gathered}
$$

In the above equations, $\Gamma$ is the compressibility correction term and $P D$ is the pressure dilatation term. $\Gamma=\boldsymbol{\alpha}_{1} M_{t}^{2}$ for Sarkar [22] model, and $\Gamma=\boldsymbol{\alpha}_{1}\left(M_{t}^{2}-M_{t_{0}}^{2}\right) H\left(M_{t}-M_{t_{0}}\right)$ for Wilcox [23] model.

$$
M_{t}=\frac{\sqrt{2 k}}{a}, \quad a=\sqrt{\frac{\gamma p}{\rho}}
$$

$H(x)$ is Heaviside step function. $H(x)=0$ for $M_{t} \leq M_{t_{0}}$ and $H(x)=3 / 2$ for $M_{t}>M_{t_{0}}, M_{t_{0}}=0.25$

$$
P D=-\rho \overline{u_{i} u_{j}} \frac{\partial u_{j}}{\partial x_{i}}\left(-\alpha_{2} M_{t}^{2}\right)+\frac{\mathrm{Re}_{\tilde{L}}}{M_{\infty}} \rho \varepsilon\left(\boldsymbol{\alpha}_{3} M_{t}^{2}\right)
$$

$\boldsymbol{\alpha}_{1}=1.0, \boldsymbol{\alpha}_{2}=0.4, \quad \boldsymbol{\alpha}_{3}=0.2$ following Ref. [24].

$$
f_{2}=1 .-0.3 \exp \left(-R_{t}^{2}\right), \quad R_{t}=\frac{k^{2}}{\boldsymbol{v}_{l} \boldsymbol{\varepsilon}}
$$

The boundary conditions for $k$ and $\varepsilon$ at the wall are:

$$
\begin{aligned}
& k_{\text {wall }}=0, \quad \boldsymbol{\varepsilon}_{\text {wall }}=\left(\frac{M_{\infty}}{\operatorname{Re}_{\tilde{L}}}\right)^{2} 2 \boldsymbol{v}_{l}\left(\frac{\partial \sqrt{k}}{\partial n}\right)^{2} \\
& \boldsymbol{v}_{t}=f_{\mu} C_{\mu}^{*} \frac{k^{2}}{\varepsilon}, \quad f_{\mu}=\exp \left[\frac{-3.41}{\left(1+\frac{R_{t}}{50}\right)^{2}}\right]
\end{aligned}
$$

$C_{\mu}^{*}$ is 0.09 for the linear model and is a function of vorticity, as well as strain tensors, for the nonlinear models. For the temperature-corrected linear model, $C_{\mu}^{*}$ is a function of stagnation temperature gradient; the exact functional relationship will be described later.

The turbulent stress components for the linear model are formulated as: 


$$
\overline{u_{i} u_{j}}=\frac{M_{\infty}}{\operatorname{Re}_{\tilde{L}}} 2 \boldsymbol{v}_{t} S_{i j}-\frac{2}{3} \boldsymbol{\delta}_{i j} k, \quad S_{i j}=\frac{1}{2}\left[\frac{\partial u_{i}}{\partial x_{j}}+\frac{\partial u_{j}}{\partial x_{i}}\right]-\frac{1}{3} \boldsymbol{\delta}_{i j} \frac{\partial u_{i}}{\partial x_{j}}
$$

In the SZL nonlinear model [16], the turbulent stresses are given by:

$$
-\overline{u_{i} u_{j}}=\frac{M_{\infty}}{\operatorname{Re}_{\tilde{L}}} 2 \boldsymbol{v}_{t} S_{i j}-\frac{2}{3} \boldsymbol{\delta}_{i j} k-2 \boldsymbol{\beta} \frac{k^{3}}{\varepsilon^{2}}\left(\frac{M_{\infty}}{\operatorname{Re}_{\tilde{L}}}\right)^{2}\left(W_{i k} S_{k j}-S_{i k} W_{k j}\right)
$$

Girimaji nonlinear model [17] is given by:

$$
\begin{gathered}
-\overline{u_{i} u_{j}}=\frac{M_{\infty}}{\operatorname{Re}_{\tilde{L}}} 2 \boldsymbol{v}_{t} S_{i j}-\frac{2}{3} \boldsymbol{\delta}_{i j} k-2 C_{\mu}^{*} \frac{k^{3}}{\varepsilon^{2}}\left(\frac{M_{\infty}}{\operatorname{Re}_{\tilde{L}}}\right)^{2}\left[G_{2}\left(W_{i k} \bar{S}_{k j}-\bar{S}_{i k} W_{k j}\right)+G_{3}\left(\bar{S}_{i k} \bar{S}_{k j}-\frac{1}{3} \bar{S}_{m n} \bar{S}_{m n} \boldsymbol{\delta}_{i j}\right)\right] \\
W_{i j}=\frac{1}{2}\left(\frac{\partial u_{i}}{\partial x_{j}}-\frac{\partial u_{j}}{\partial x_{i}}\right), \quad \bar{S}_{i j}=\frac{1}{2}\left[\frac{\partial u_{i}}{\partial x_{j}}+\frac{\partial u_{j}}{\partial x_{i}}\right]
\end{gathered}
$$

The variables such as $\beta, C_{\mu}^{*}, G_{2}, G_{3}$ have been defined in the Appendix. In the temperature-corrected model [25], $C_{\mu}^{*}$ is prescribed as,

$$
\begin{aligned}
C_{\mu}^{*} & =0.09 C_{T} \\
C_{T} & =\left[1+\frac{T_{g}^{3}}{0.041+f\left(M_{t}\right)}\right], \quad f\left(M_{t}\right)=\left(M_{t}^{2}-M_{t_{0}}^{2}\right) H\left(M_{t}-M_{t_{0}}\right), \quad M_{t_{0}}=0.1 \\
T_{g} & =\sqrt{\left(\frac{\partial T_{t}}{\partial x_{i}}\right)^{2}}\left(\frac{k^{3 / 2}}{\varepsilon}\right) \frac{M_{\infty}}{\operatorname{Re}_{\tilde{L}}} / T_{t}
\end{aligned}
$$

In the above formula, $T_{t}$ is stagnation temperature.

\section{SST Model}

$$
\begin{aligned}
& \frac{\partial \rho k}{\partial t}+\frac{\partial \rho u_{i} k}{\partial x_{i}}=\frac{M_{\infty}}{\operatorname{Re}_{\tilde{L}}} \rho \boldsymbol{v}_{t} \boldsymbol{\Omega}^{2}+\frac{M_{\infty}}{\operatorname{Re}_{\tilde{L}}} \frac{\partial}{\partial x_{i}}\left[\rho\left(\boldsymbol{v}_{l}+\boldsymbol{\sigma}_{k} \boldsymbol{v}_{t}\right) \frac{\partial k}{\partial x_{i}}\right]-\frac{\operatorname{Re}_{\tilde{L}}}{M_{\infty}} \boldsymbol{\beta}^{*} \rho k \omega\left(1+\left(1-F_{1}\right) \Gamma\right)+\left(1-F_{1}\right) P D_{k} \\
& \frac{\partial \rho \omega}{\partial t}+\frac{\partial \rho u_{i} \omega}{\partial x_{i}}=\frac{M_{\infty}}{\operatorname{Re}_{\tilde{L}}} \gamma \rho \Omega^{2}+\frac{M_{\infty}}{\operatorname{Re}_{\tilde{L}}} \frac{\partial}{\partial x_{i}}\left[\rho\left(\boldsymbol{v}_{l}+\sigma_{\omega} \boldsymbol{v}_{t}\right) \frac{\partial \omega}{\partial x_{i}}\right]-\frac{\operatorname{Re}_{\tilde{L}}}{M_{\infty}} \rho \omega^{2}\left(\beta-\left(1-F_{1}\right) \beta^{*} \Gamma\right)+ \\
& \frac{M_{\infty}}{\operatorname{Re}_{\tilde{L}}} 2\left(1-F_{1}\right) \rho \sigma_{\omega 2} \frac{1}{\omega} \frac{\partial k}{\partial x_{i}} \frac{\partial \omega}{\partial x_{i}}+\left(1-F_{1}\right) P D_{\omega} \\
& P D_{k}=-\frac{M_{\infty}}{\operatorname{Re}_{\tilde{L}}} \boldsymbol{\rho} \boldsymbol{v}_{t} \boldsymbol{\Omega}^{2} \boldsymbol{\alpha}_{2} M_{t}^{2}+\frac{\mathrm{Re}_{\tilde{L}}}{M_{\infty}} \boldsymbol{\rho} \boldsymbol{\beta}^{*} k \omega \boldsymbol{\alpha}_{3} M_{t}^{2} \\
& P D_{\boldsymbol{\omega}}=\frac{M_{\infty}}{\operatorname{Re}_{\tilde{L}}} \boldsymbol{\rho} \boldsymbol{\Omega}^{2} \boldsymbol{\alpha}_{2} M_{t}^{2}-\frac{\operatorname{Re}_{\tilde{L}}}{M_{\infty}} \boldsymbol{\rho} \boldsymbol{\omega}^{2} \boldsymbol{\beta}^{*} \boldsymbol{\alpha}_{3} M_{t}^{2}
\end{aligned}
$$




$$
\boldsymbol{\Omega}=\sqrt{2 \boldsymbol{\Omega}_{i j} \boldsymbol{\Omega}_{i j}}, \quad \boldsymbol{\Omega}_{i j}=\frac{1}{2}\left[\frac{\partial u_{i}}{\partial x_{j}}-\frac{\partial u_{j}}{\partial x_{i}}\right]
$$

The constants $\sigma_{k}, \sigma_{\omega}, \gamma$, and $\beta$ are evaluated using the general formula $\phi=F_{1} \phi_{1}+\left(1-F_{1}\right) \phi_{2}$. The parameters $\phi_{1}$ and $\phi_{2}$ represent the values in the inner- and outer-region, respectively. The inner- and outerset constants have been defined below.

Inner set: $\sigma_{k 1}=0.85, \quad \sigma_{\omega 1}=0.5, \quad \gamma_{1}=5 / 9, \quad \beta_{1}=\left(\gamma_{1}+\frac{\sigma_{\omega 1} \kappa^{2}}{\sqrt{\beta^{*}}}\right) \beta^{*}=0.075215$

Outer set: $\boldsymbol{\sigma}_{k 2}=1.0, \quad \sigma_{\omega 2}=0.857, \quad \gamma_{2}=0.44, \quad \boldsymbol{\beta}_{2}=\left(\gamma_{2}+\frac{\sigma_{\omega 2} \boldsymbol{K}^{2}}{\sqrt{\boldsymbol{\beta}^{*}}}\right) \boldsymbol{\beta}^{*}=0.08281851$

$\beta^{*}=0.09, \quad \kappa=0.41$

$$
\begin{gathered}
F_{1}=\tanh \left(\Psi^{4}\right), \quad \Psi=\min \left(\max \left(\Psi_{1}, \Psi_{3}\right), \Psi_{2}\right) \\
\Psi_{1}=\frac{500 \boldsymbol{v}_{l}}{\boldsymbol{\omega} d^{2}}\left(\frac{M_{\infty}}{\operatorname{Re}_{\tilde{L}}}\right)^{2}, \quad \Psi_{2}=\frac{4 \rho \sigma_{\omega 2} k}{C D_{k \omega} d^{2}}, \quad \Psi_{3}=\frac{\sqrt{k}}{\beta^{*} \omega d}\left(\frac{M_{\infty}}{\operatorname{Re}_{\tilde{L}}}\right) \\
C D_{k \omega}=\left(2 \rho \sigma_{\omega 2} \frac{1}{\omega} \frac{\partial k}{\partial x_{i}} \frac{\partial \omega}{\partial x_{i}}, 1 \times 10^{-20}\right) \\
\boldsymbol{v}_{t}=\min \left(\frac{k}{\omega}, \frac{\operatorname{Re}_{\tilde{L}}}{M_{\infty}} \frac{a_{1} k}{\Omega F_{2}}\right) \\
F_{2}=\tanh \left(\Pi^{2}\right), \quad \Pi=\max \left(2 \Psi_{3}, \Psi_{1}\right)
\end{gathered}
$$

\section{Results and Discussion}

\section{A. Eggers Nozzle}

The initial assessment of the present method is performed on a fully expanded supersonic cold free jet case that was experimentally investigated by Eggers [26]. This study involved a Mach 2.22 axisymmetric nozzle exhausting to quiescent air at the design pressure ratio. The total temperature of the jet was the same as the ambient temperature of $525^{\circ} \mathrm{R}$. For the numerical investigation, a fully unstructured tetrahedral grid was generated with normal-direction grid spacing equivalent to an average cell-center $\mathrm{y}^{+}=0.20$ at the nozzle wall. The grid was generated inside one quadrant of the nozzle, and the symmetry-plane boundary condition was applied on two planes defining the quadrant. The tetrahedral grid consists of 1,313,752 cells, 242,567 nodes, and 82,106 boundary triangles. A view of the surface grid on one of the symmetry planes is presented in Fig. 1.

The computed solutions for this case were obtained by considering a freestream Mach number of 0.05 to avoid the solution instability and convergence difficulty encountered by a compressible flow solver USM3D at very low speed. All three turbulence models, namely, Spalart-Allmaras (SA) one-equation model, Launder-Sharma $k-\varepsilon$ linear model, and Menter SST model were applied in various computed solutions. The SA model was applied in its standard form without incorporating any modifications to either the equation itself or to the coefficients used in the equation. Both of the two-equation models were applied in their standard forms as well as in their modified forms that include pressure dilatation term along with compressible dissipation formulation of either Sarkar or Wilcox. For the sake of brevity, the enhanced model using Sarkar formulation will be denoted as "Sarkar_PD", and that using Wilcox formulation will be denoted as "Wilcox_PD" in the remainder of this section. Figure 2 presents the convergence of mean-flow residual errors for all of the computed solutions obtained for this case. The SA model converges monotonically whereas $k-\varepsilon$ as well as SST models exhibit stalled convergence after about 3.5 orders of magnitude reduction in residual errors. Symmetry plane variations of Mach number, as obtained from the 
SA, $k$ - $\varepsilon$ Sarkar_PD, and Menter SST Sarkar_PD models, are depicted in Fig. 3. It is evident from this figure that the $k-\varepsilon$ Sarkar_PD model predicts a slightly longer potential core region as compared to that from the SA and SST Sarkar_PD models.

Figures 4 and 5 present a detailed comparison of the computed and measured velocity profiles along the nozzle centerline, as well as along the radial direction at several axial locations. The standard SA model result is included here for reference, since it is a widely used turbulence model for computational applications. In Fig. 4, predicted velocity profiles from the standard $k-\varepsilon, k-\varepsilon$ Sarkar_PD, and $k-\varepsilon$ Wilcox_PD models are compared with the corresponding SA model predictions and the measurements of Eggers. Figure 5 presents a comparison of the predicted velocity profiles from the standard SST, SST Sarkar_PD, SST Wilcox_PD, and SA models, as well as the measurements of Eggers. It is evident from both figures that the addition of pressure dilatation term and compressible dissipation correction markedly improves the accuracy of the solutions based on $k-\varepsilon$ and Menter SST models relative to the standard versions. Amongst the two formulations for compressible dissipation, the $k-\varepsilon$ model yields slightly better accuracy with the Wilcox formulation in the vicinity of the centerline. However, Sarkar formulation is in closer agreement to the measurements far away from the centerline. The SST model performs better with the Sarkar formulation. It is also seen that the predictions of radial spread of jet are in quite good agreement with the measurements up to the axial locations of 75 times the nozzle exit radius. It should be recalled that due to the limitation imposed by the compressible flow solver, the computations have been performed assuming a freestream Mach of 0.05 as opposed to using quiescent air condition of the experiment. This discrepancy may have been responsible for the poor agreement of the computations and measurements at the axial station located at $\mathrm{x} / \mathrm{r}_{\text {exit }}=121.30$.

\section{B. Seiner Nozzle}

This axisymmetric supersonic jet test case was experimentally investigated by Seiner [27]. The nozzle was operated at the design pressure condition over a wide range of plenum temperature. The nozzle exit Mach number was 2 , and plenum temperature ranged from $563{ }^{\circ} \mathrm{R}$ to $2459{ }^{\circ} \mathrm{R}$. This test case has been selected to assess the temperature correction formulation presently implemented in the $k$ - $\varepsilon$ turbulence model. Computations have been performed for the nozzle plenum temperatures of $563{ }^{\circ} \mathrm{R}, 1359{ }^{\circ} \mathrm{R}$ and $2009^{\circ} \mathrm{R}$. Computed results for the plenum temperature of $563{ }^{\circ} \mathrm{R}$ will be shown first to assess the impact, if any, of temperature correction formulation on the cold jet. The results for the plenum temperature of 2009 ${ }^{\circ} \mathrm{R}$ will be presented next, as this specific condition was used in the calibration of the temperature correction model in Ref. [25]. This study will establish that no further tuning of the model is warranted due to different solution methodology employed in various CFD codes. Finally, the computational results will be presented for an intermediate plenum temperature of $1359{ }^{\circ} \mathrm{R}$ to assess whether the model remains effective at a plenum temperature different from the one used for the model calibration. Only the $k-\varepsilon$ turbulence model has been used in the computations. However, several different variants of $k-\varepsilon$ models such as the standard formulation, Sarkar_PD, and Wilcox_PD formulations - with and without temperature correction term - have been applied.

A fully unstructured tetrahedral grid was generated inside one quadrant of the nozzle and symmetryplane boundary condition was applied on two planes defining the quadrant. The normal-direction grid spacing equivalent to an average cell-center $\mathrm{y}^{+}=0.12$ was applied at the nozzle wall. The tetrahedral grid consists of 2,706,755 cells, 496,241 nodes, and 157,172 boundary triangles. Identical grid has been used for computing the cold as well as hot jet solutions. Although not shown, all solutions converged to a level of about 3.5 orders of reduction in the mean-flow residual errors.

Figure 6 shows the comparison of the computed and measured profiles of Mach number and stagnation pressure along the nozzle centerline for the cold jet case. It is evident from the figure that the solutions obtained with and without temperature correction model are almost identical. This is only to be expected as the total temperature of nozzle plenum is identical to that of ambient air, and the flow should be devoid of total temperature gradients to activate the temperature correction model. It is observed from the figure that the Sarkar_PD formulation compares very well with the measured data.

Next, the accuracy of the present temperature correction formulation is assessed via two hot jet cases. Initially, nozzle plenum stagnation temperature of $2009{ }^{\circ} \mathrm{R}$ has been used for this purpose. Figure $7 \mathrm{a}$ presents symmetry-plane variation of the normalized stagnation temperature. It can be seen that the stagnation temperature gradient locates itself in the shear layer region. In the present temperature correction 
formulation, this gradient is used for increasing the $C_{\mu}^{*}$ in the shear layer region as shown in Fig. 7b. The increased $C_{\mu}^{*}$ results in the increased eddy viscosity that produces enhanced mixing in the shear layer. Figure 8 presents a comparison of the computed and measured centerline variations of Mach number, stagnation pressure, and stagnation temperature for the nozzle plenum temperature of $2009^{\circ} \mathrm{R}$. It is clear from this figure that the temperature correction formulation in conjunction with the Sarkar_PD model provides a very good comparison with the measured data. Further assessment of the temperature correction model is performed using an intermediate temperature of $1359^{\circ} \mathrm{R}$ for the nozzle plenum. Figure 9 depicts favorable comparisons of the centerline variations of Mach number, stagnation pressure, and stagnation temperature obtained from the temperature-corrected Sarkar_PD computations and the experimental measurements. It can be concluded from Fig. 6,8 and 9 that the temperature correction model provides reasonable and consistent correlation with the measured data across the temperature range, from ambient to $2009^{\circ} \mathrm{R}$.

\section{Concluding Remarks}

The two-equation turbulence models in the TetrUSS USM3D Navier-Stokes flow solver have been extended to account for compressibility and temperature effects. These extensions were implemented in response to a need in the NASA Constellation program to improve the aerodynamic and loads prediction capability of the solver for jet-dominated flows that are often encountered on the ARES Crew Launch Vehicle and Orion Launch Abort Vehicle.

The standard forms of $k-\varepsilon$ and SST two-equation turbulence models are enhanced with selected published compressibility correction and pressure dilatation terms, and assessed on two supersonic cold jet cases at design pressure conditions. These studies have shown that while the standard form of two-equation model offers no apparent advantage over the SA one-equation model, incorporation of the compressibility correction and the pressure dilatation terms significantly improves the accuracy of jet spreading rates predicted by the two- equation models.

A temperature correction formulation is also implemented in the $k$ - $\varepsilon$ model to improve the computational accuracy for hot jets. Good correlation with experimental data has been demonstrated for three different temperatures of nozzle plenum for a supersonic jet case at the design pressure condition.

Additional work is underway to evaluate the new turbulence model extensions for subsonic/transonic jet flows. Meanwhile, this new capability is currently in heavy use within the NASA Constellation program.

\section{Appendix}

The following functions and variables are used in the SZL [16] algebraic Reynolds stress model:

$$
\begin{gathered}
C_{\mu}^{*}=\frac{1}{\left(6.5+A_{s}^{*} \frac{U^{*} k}{\varepsilon}\right)} \\
A_{s}^{*}=\sqrt{6} \cos (\phi), \quad \phi=\frac{1}{3} \cos ^{-1}\left(\sqrt{6} S^{*}\right), \quad S^{*}=S_{i j} S_{j k} S_{k i} /(S)^{3}, \quad S=\sqrt{S_{i j} S_{i j}} \\
U^{*}=\sqrt{S_{i j} S_{i j}+W_{i j} W_{i j}}, \quad W=\sqrt{W_{i j} W_{i j}} \\
\beta=\frac{\sqrt{1-9 C_{\mu}^{*}\left(\frac{S k}{\varepsilon}\right)^{2}}}{\left(1+6 \frac{S k}{\varepsilon} \frac{W k}{\varepsilon}\right)}
\end{gathered}
$$


For the Girimaji [17] model:

$$
\begin{aligned}
& L_{1}^{0}=\frac{C_{1}^{0}}{2}-1, \quad L_{1}^{1}=C_{1}^{1}+2, \quad L_{2}=\frac{C_{2}}{2}-\frac{2}{3}, \quad L_{3}=\frac{C_{3}}{2}-1, \quad L_{4}=\frac{C_{4}}{2}-1 \\
& C_{1}^{0}=3.4, \quad C_{1}^{1}=1.8, \quad C_{2}=0.36, \quad C_{3}=1.25, \quad C_{4}=0.4 \\
& \boldsymbol{\eta}_{1}=\left(\frac{k}{\varepsilon}\right)^{2} \bar{S}_{m n} \bar{S}_{m n}, \quad \boldsymbol{\eta}_{2}=\left(\frac{k}{\varepsilon}\right)^{2} W_{m n} W_{m n} \\
& p=-\frac{2 L_{1}^{0}}{\boldsymbol{\eta}_{1} L_{1}^{1}}, \quad q=\frac{1}{\left(\boldsymbol{\eta}_{1} L_{1}^{1}\right)^{2}}\left[\left(L_{1}^{0}\right)^{2}+\boldsymbol{\eta}_{1} L_{1}^{1} L_{2}-\frac{2}{3} \boldsymbol{\eta}_{1}\left(L_{3}\right)^{2}+2 \boldsymbol{\eta}_{2}\left(L_{4}\right)^{2}\right], \quad r=-\frac{L_{1}^{0} L_{2}}{\left(\boldsymbol{\eta}_{1} L_{1}^{1}\right)^{2}} \\
& a=\left(q-\frac{p^{2}}{3}\right), \quad b=\frac{1}{27}\left(2 p^{3}-9 p q+27 r\right), \quad D=\frac{b^{2}}{4}+\frac{a^{3}}{27}, \quad \cos (\boldsymbol{\theta})=\frac{-b / 2}{\sqrt{-a^{3} / 27}} \\
& G_{1}=\left\{\begin{array}{l}
L_{1}^{0} L_{2}\left[\left(L_{1}^{0}\right)^{2}+2 \boldsymbol{\eta}_{2}\left(L_{4}\right)^{2}\right] \text { for } \boldsymbol{\eta}_{1}=0 \\
L_{1}^{0} L_{2} /\left[\left(L_{1}^{0}\right)^{2}+\frac{2}{3} \boldsymbol{\eta}_{1}\left(L_{3}\right)^{2}+\boldsymbol{\eta}_{2}\left(L_{4}\right)^{2}\right] \text { for } L_{1}^{1}=0 \\
-\frac{p}{3}+\left(-\frac{b}{2}+\sqrt{D}\right)^{1 / 3}+\left(-\frac{b}{2}-\sqrt{D}\right)^{1 / 3} \text { for } D>0 \\
-\frac{p}{3}+2 \sqrt{\frac{-a}{3}} \cos \left(\frac{\boldsymbol{\theta}}{3}\right) \text { for } D<0 \text { and } b<0 \\
-\frac{p}{3}+2 \sqrt{\frac{-a}{3}} \cos \left(\frac{\boldsymbol{\theta}}{3}+\frac{2 \pi}{3}\right) \text { for } D<0 \text { and } b>0
\end{array}\right. \\
& C_{\mu}^{*}=-G_{1} \\
& G_{2}=\frac{-L_{4}}{L_{1}^{0}-\eta_{1} L_{1}^{1} G_{1}}, \quad G_{3}=\frac{-2 L_{3}}{L_{1}^{0}-\eta_{1} L_{1}^{1} G_{1}}
\end{aligned}
$$

\section{Acknowledgments}

The authors would like to thank Jan-Renee Carlson of NASA Langley Research Center for providing Eggers nozzle GridTool model, and Shahyar Pirzadeh of NASA Langley Research Center and Edward Parlette of ViGYAN, Inc. for the grid generation help. The first author would like to thank NASA's Orion Project, Constellation Program, Subsonic Fixed Wing Project, Fundamental Aeronautics Program, and Integrated Resilient Aircraft Control Project, Aviation Safety Program for the funding needed to perform the present study.

\section{References}

[1] Frink, N.T., Pirzadeh, S.Z., Parikh, P.C., and Pandya, M.J., "The NASA Tetrahedral Unstructured Software System (TetrUSS)," The Aeronautical Journal, Vol. 104, No. 1040, October 2000, pp. 491499.

[2] Samareh, J., "GridTool: A Surface Modeling and Grid Generation Tool," Proceedings of the Workshop on Surface Modeling, Grid Generation, and Related Issues in CFD Solutions, NASA CP3291, 9-11 May, 1995. 
[3] Pirzadeh, S., "Structured Background Grids for Generation of Unstructured Grids by Advancing Front Method," AIAA Journal, Vol. 31, No. 2, February 1993, pp. 257-265.

[4] Pirzadeh, S., "Unstructured Viscous Grid Generation by Advancing-Layers Method," AIAA Journal, Vol. 32, No. 8, August 1994, pp. 1735-1737.

[5] Frink, N. T., "Upwind Scheme for Solving the Euler Equations on Unstructured Tetrahedral Meshes," AIAA Journal, Vol., No. 1, January 1992, pp. 70-77.

[6] Frink, N. T., "Tetrahedral Unstructured Navier-Stokes Method for Turbulent Flows," AIAA Journal, Vol. 36, No. 11, November 1998, pp. 1975-1982.

[7] Roe, P., "Characteristic Based Schemes for the Euler Equations," Annual Review of Fluid Mechanics, Vol. 18, 1986, pp. 337-365.

[8] Liou, M.-S., "A Continuing Search for a Near-Perfect Numerical Flux Scheme. Part 1: AUSM+," NASA TM 106524, March 1994.

[9] Batten, P., Leschziner, M. A., and Goldberg, U. C., "Average-State Jacobians and Implicit Methods for Compressible Viscous and Turbulent Flows," Journal of Computational Physics, Vol. 137, No. 1, October 1997, pp. 38-78.

[10]Frink, N. T., "Recent Progress Toward a Three-Dimensional Unstructured Navier-Stokes Flow Solver," AIAA Paper 94-0061, January 1994.

[11] Anderson, W.; and Bonhaus D., "An Implicit Upwind Algorithm for Computing Turbulent Flows on Unstructured Grids," Computers Fluids, Vol. 23, No. 1, 1994, pp. 1-21.

[12] Spalart P., and Allmaras S. A., "One-Equation Turbulence Model for Aerodynamic Flows," AIAA Paper 92-0439, January 1992.

[13] Jones, W. P., and Launder, B. E., "The Prediction of Laminarization with a Two-Equation Model of Turbulence," Int. J. Heat \& Mass Transf., Vol. 15, No. 2, February 1972, pp. 301-314.

[14] Menter, F.R., "Improved Two-Equation k-omega Turbulence Models for Aerodynamic Flows," NASA TM-103975, October 1992.

[15] Abdol-Hamid, K. S. Frink, N. T., Deere, K. A., and Pandya, M.J., "Propulsion Simulations Using Advanced Turbulence Models with the Unstructured-Grid CFD Tool, TetrUSS," AIAA Paper 20040714, January 2004.

[16] Shih, T-H., Zhu, J., and Lumley, J.L., “A New Reynolds Stress Algebraic Model,” NASA TM-166614, ICOMP 94-8, 1994.

[17] Girimaji, S.S., "Fully-Explicit and Self-Consistent Algebraic Reynolds Stress Model," ICASE Report 95-82, 1995.

[18] Pandya, M. J., Abdol-Hamid, K. S., Campbell, R. L., and Frink, N. T., "Implementation of Flow Tripping Capability in the USM3D Unstructured Flow Solver," AIAA Paper 2006-0919.

[19] Frink, N.T., Bonhaus, D.L., Vatsa, V.N., Bauer, S.X.S., Tinetti, A.F., "A Boundary Condition for Simulation of Flow Over Porous Surfaces," Journal of Aircraft, Vol. 40, No. 4, July-August 2003, pp. 692-698.

[20] Pandya, M.J., Frink, N.T., Abdol-Hamid, K.S., and Chung, J.J., "Recent Enhancements to USM3D Unstructured Flow Solver for Unsteady Flows," AIAA Paper 2004-5201, August 16-19 2004.

[21] Pandya, M.J., Frink, N.T., and Noack, R.W., "Overset-Grid Moving Body Capability in the USM3D Unstructured Flow Solver," AIAA Paper 2005-5118, June 6-9 2005.

[22] Sarkar, S., Erlebacher, G., Hussaini, M. Y., and Kreiss, H. O., "The Analysis and Modeling of Dilatational Terms in Compressible Turbulence," J. Fluid Mech., Vol. 227, June 1991, pp. 473-495.

[23] Wilcox, D. C., "Progress in Hypersonic Turbulence Modeling," AIAA Paper 91-1785, June 1991.

[24] Suzen, Y. B., and Hoffman, K. A., "Investigation of Supersonic Jet Exhaust Flow by One- and TwoEquation Turbulence Models," AIAA Paper 98-0322, January 1998.

[25] Abdol-Hamid, K. S., Pao, S. P., Massey, S. J., and Elmiligui, A., "Temperature Corrected Turbulence Model for High Temperature Jet Flow," ASME Journal of Fluids Engineering, Vol. 126, No. 5, September 2004, pp. 844-850.

[26] Eggers, J. M., "Velocity Profiles and Eddy Viscosity Distributions Downstream of a Mach 2.22 Nozzle Exhausting to Quiescent Air," NASA TN D-3601, September 1966.

[27] Seiner, J. M., Ponton, M. K., Jansen, B. J., and Langen, N. T., "The Effects of Temperature on Supersonic Jet Noise,” AIAA Paper 1992-02-046, May 1992. 


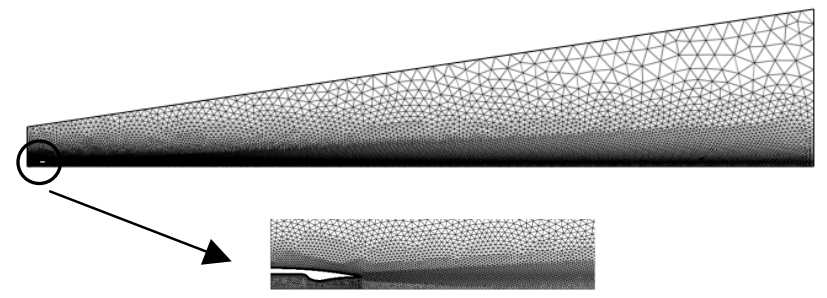

Figure 1. Symmetry-plane view of unstructured tetrahedral grid for Eggers nozzle.

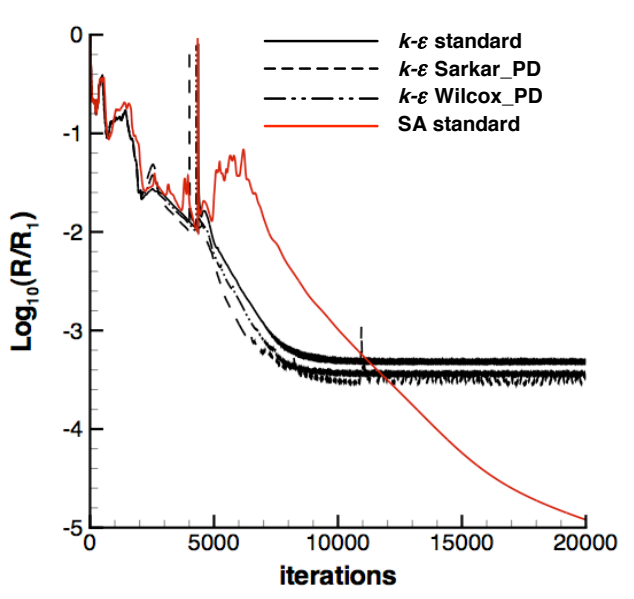

(a) $k-\varepsilon$ model

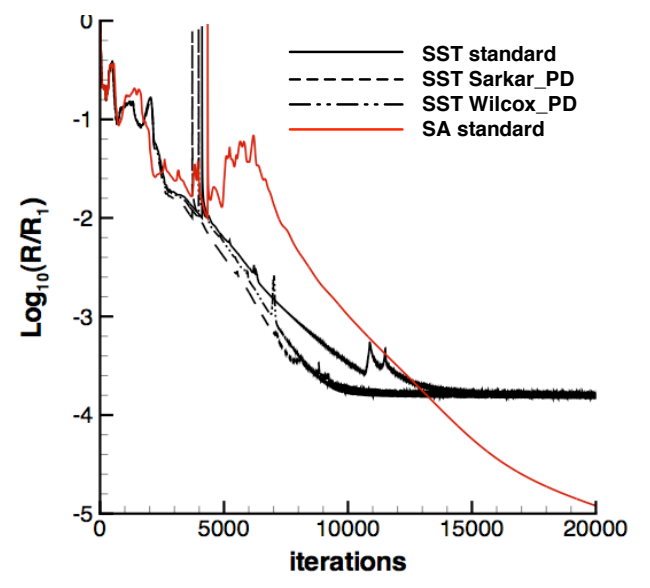

(b) SST model

Figure 2. Convergence history of mean flow residuals for SA model and (a) $k$ - $\varepsilon$ model (b) SST model.

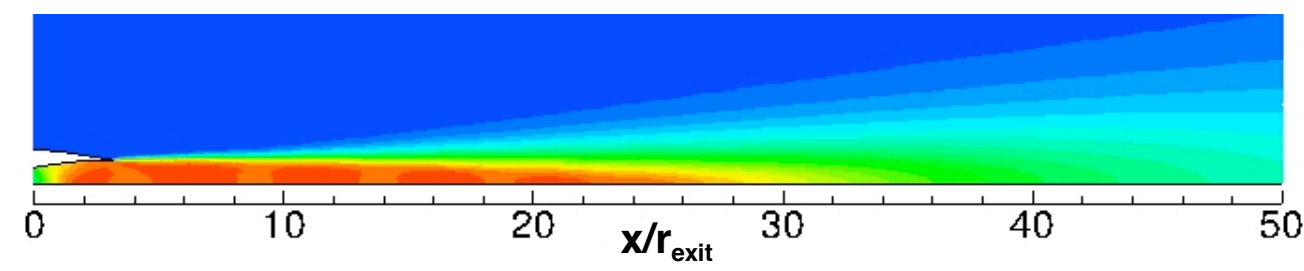

\section{(a) SA model}

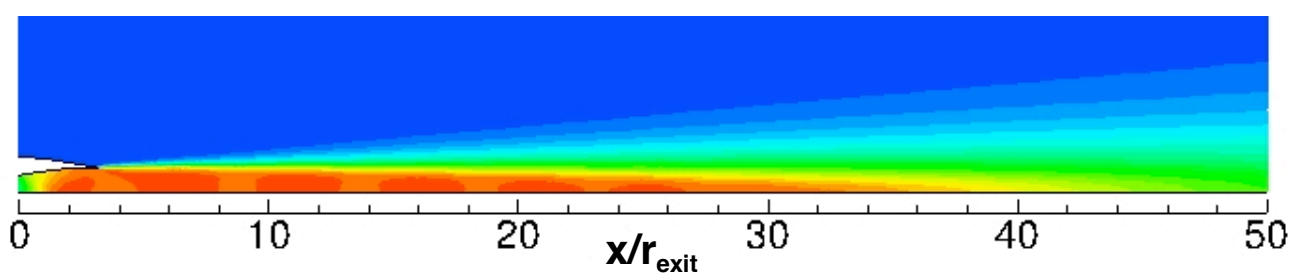

(b) $k-\varepsilon$ Sarkar_PD model

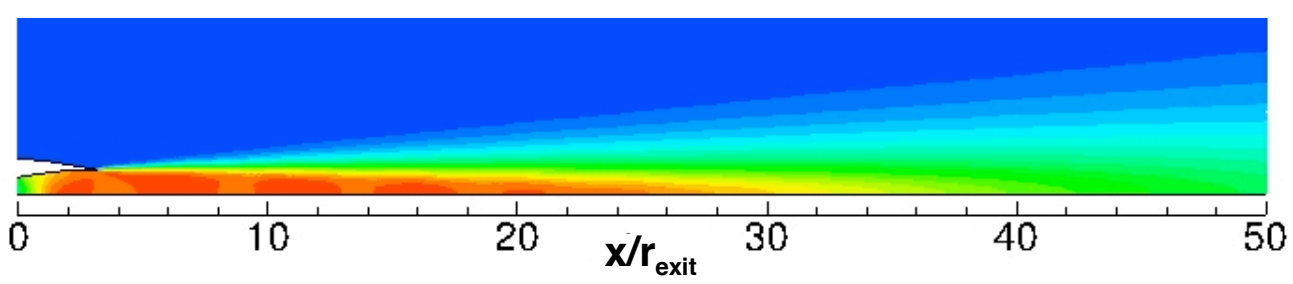

(c) SST Sarkar_PD model

Figure 3. Contours of computed Mach number on Eggers nozzle symmetry plane for (a) SA model (b) $k-\varepsilon$ model with Sarkar compressibility correction and pressure dilatation (PD) term, (c) SST model with Sarkar compressibility correction and pressure dilatation (PD) term. 


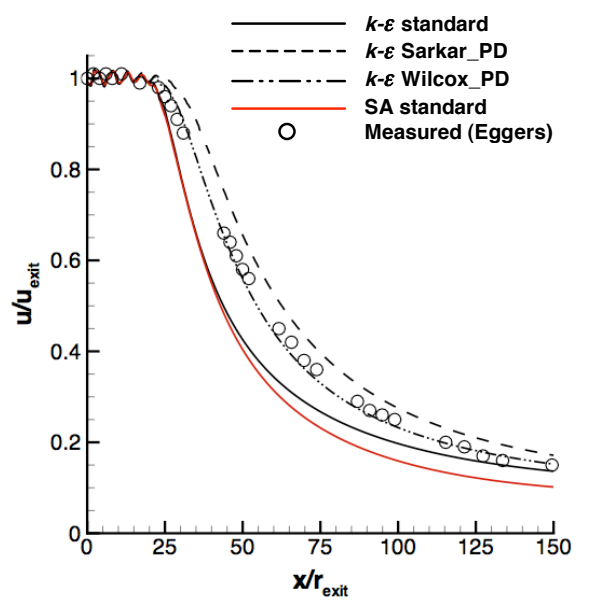

(a) Centerline profile

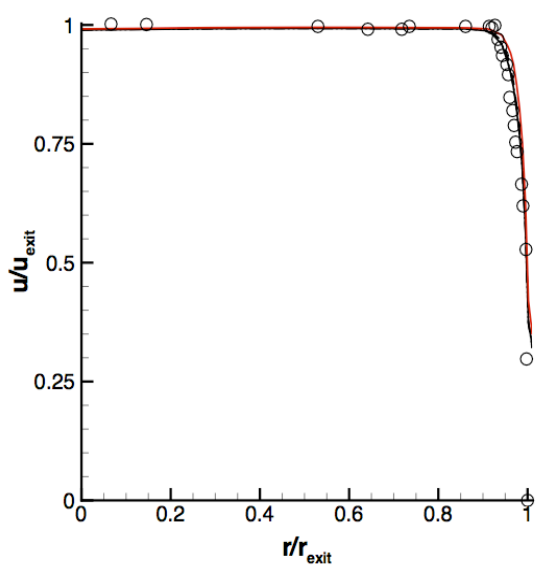

(b) Radial profile at $x / r_{\text {exit }}=0.0$

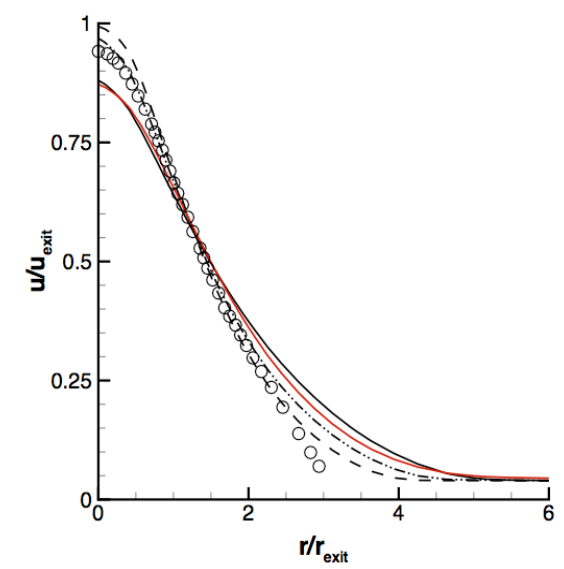

(c) Radial profile at $x / r_{\text {exit }}=\mathbf{2 6 . 9 3}$

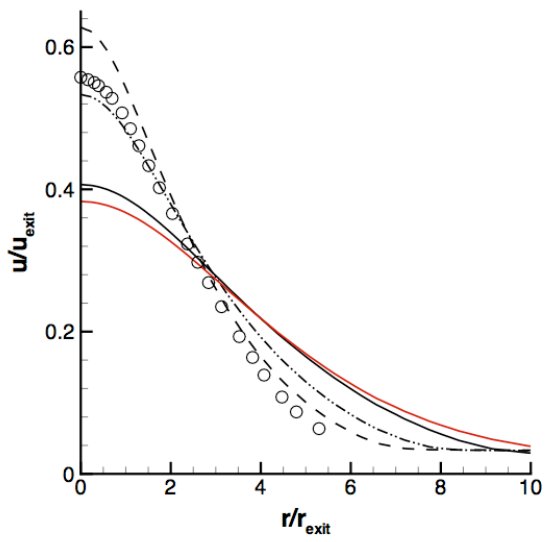

(d) Radial profile at $\mathbf{x} / \mathbf{r}_{\text {exit }}=\mathbf{5 1 . 9 6}$

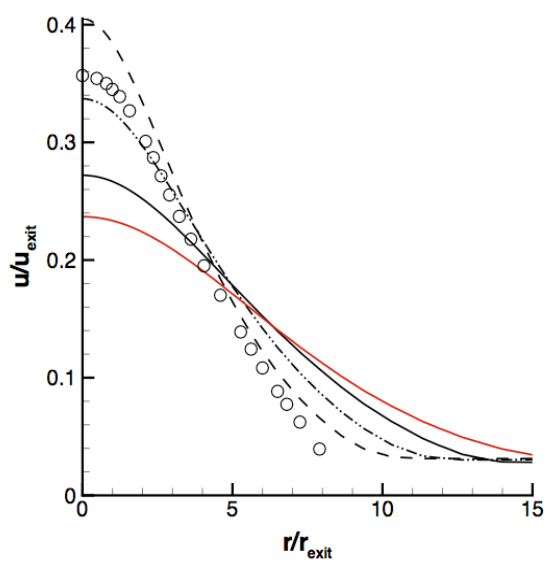

(e) Radial profile at $x / r_{\text {exit }}=73.80$

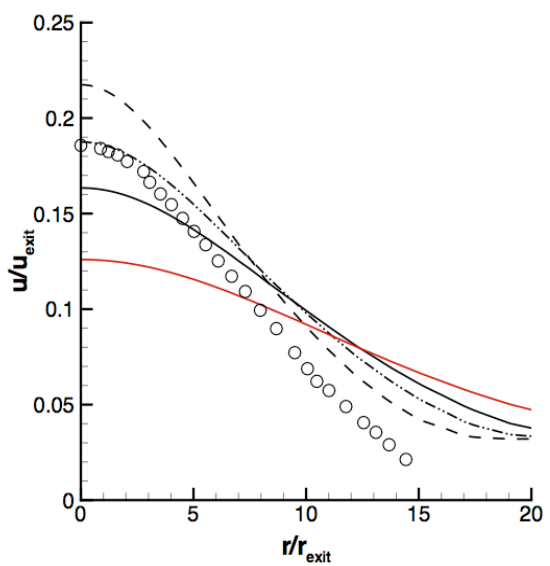

(f) Radial profile at $\mathrm{x} / \mathrm{r}_{\mathrm{exit}}=\mathbf{1 2 1 . 3 0}$

Figure 4. Comparison of computed and measured centerline/radial velocity profiles for Eggers nozzle. Computations used SA model, $k-\varepsilon$ linear model and $k-\varepsilon$ linear model enhanced with pressure dilatation (PD) term and compressibility corrections of Sarkar and Wilcox. 


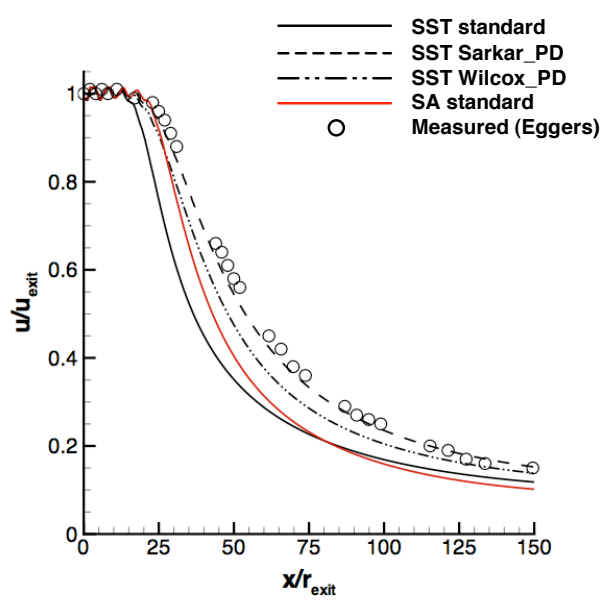

(a) Centerline profile

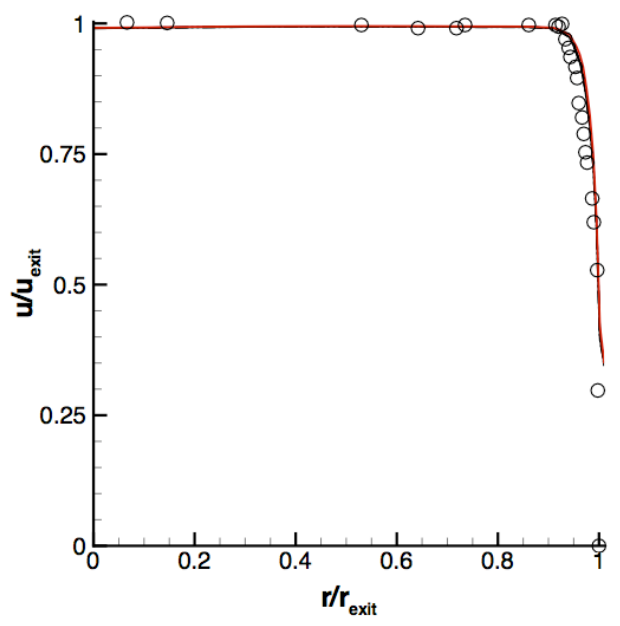

(b) Radial profile at $\mathbf{x} / \mathbf{r}_{\text {exit }}=0.0$

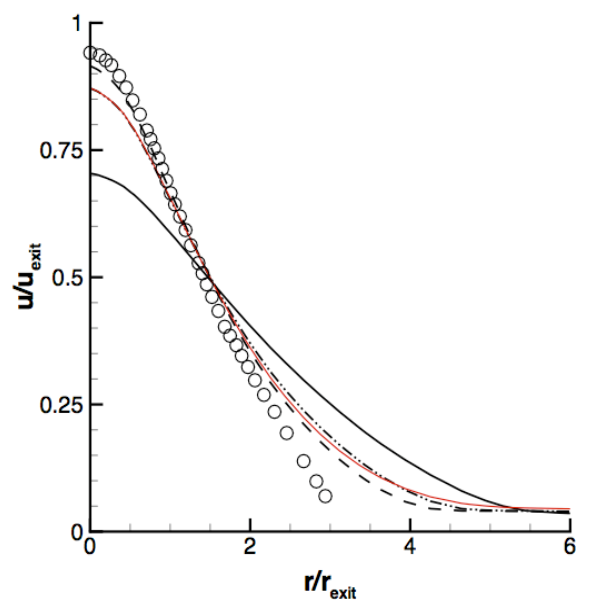

(c) Radial profile at $x / r_{\text {exit }}=\mathbf{2 6 . 9 3}$

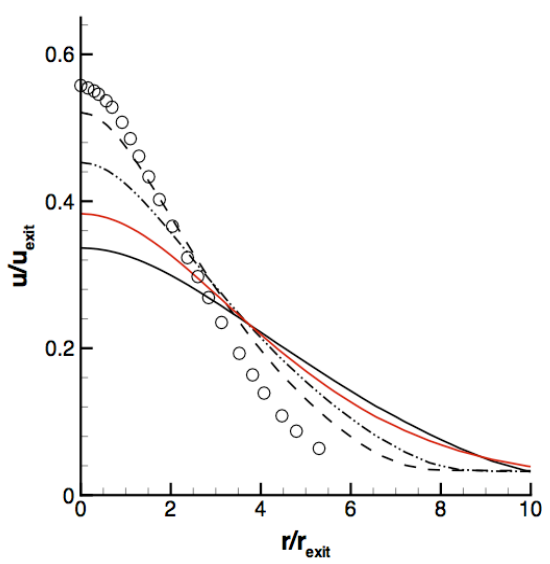

(d) Radial profile at $\mathbf{x} / \mathbf{r}_{\text {exit }}=\mathbf{5 1 . 9 6}$

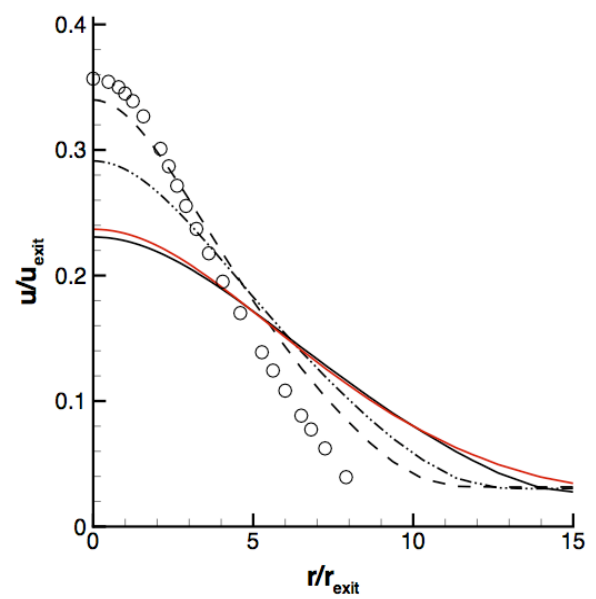

(e) Radial profile at $x / r_{\text {exit }}=73.80$

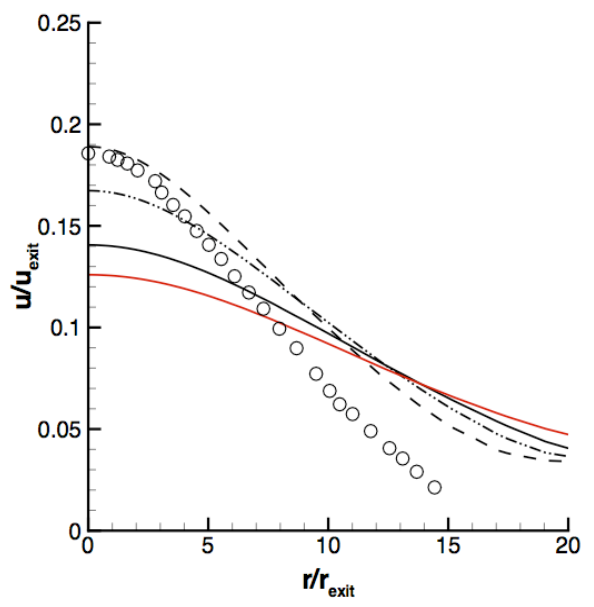

(f) Radial profile at $\mathbf{x} / \mathbf{r}_{\text {exit }}=\mathbf{1 2 1 . 3 0}$

Figure 5. Comparison of computed and measured centerline/radial velocity profiles for Eggers nozzle. Computations used SA model, SST model and SST model enhanced with pressure dilatation (PD) term and compressibility corrections of Sarkar and Wilcox. 


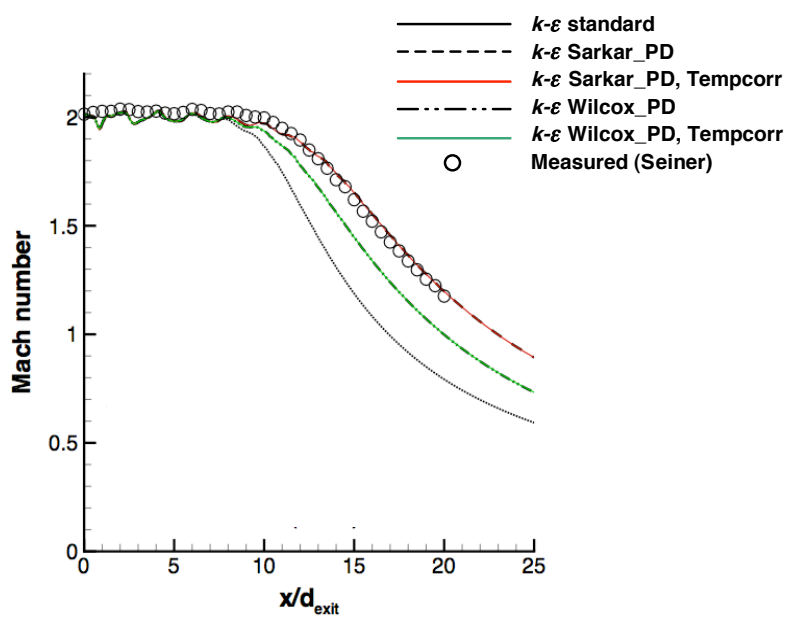

(a) Mach number

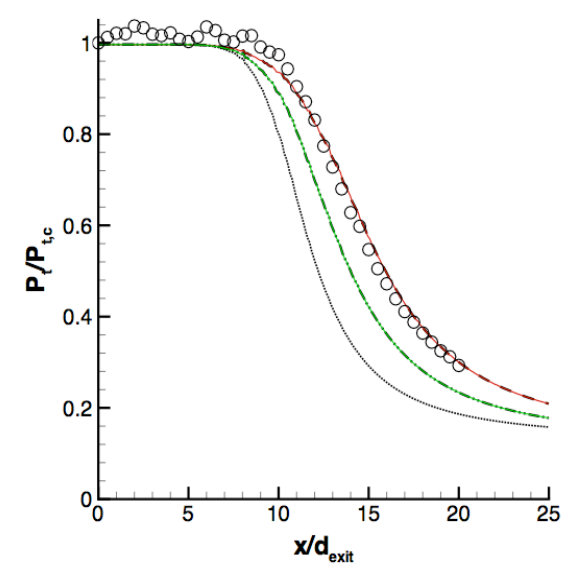

(b) Stagnation pressure ratio, $\mathbf{P}_{\mathbf{t}} / \mathbf{P}_{t, c}$

Figure 6. Comparison of Seiner nozzle's computed and measured centerline profiles for nozzle plenum stagnation temperature of $563{ }^{\circ} \mathrm{R}$.

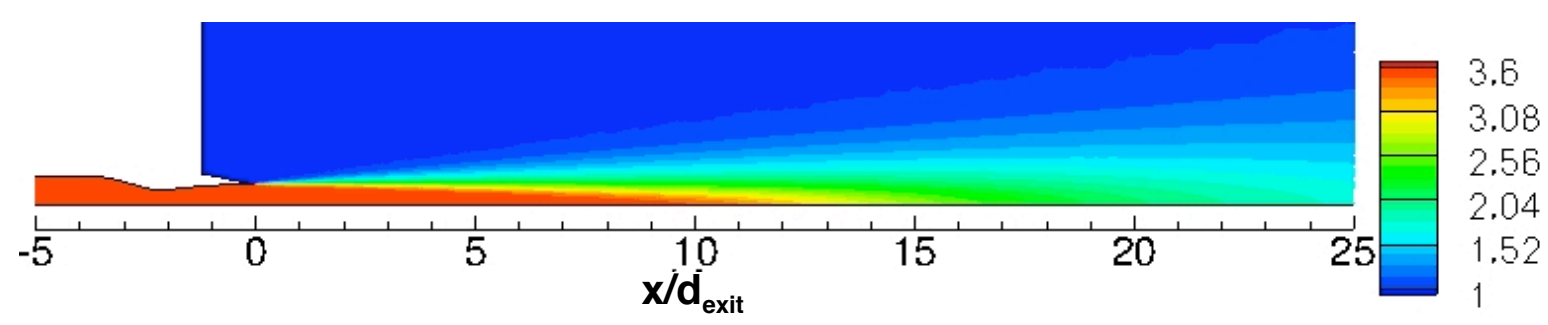

(a) Normalized stagnation temperature, $T_{t}$

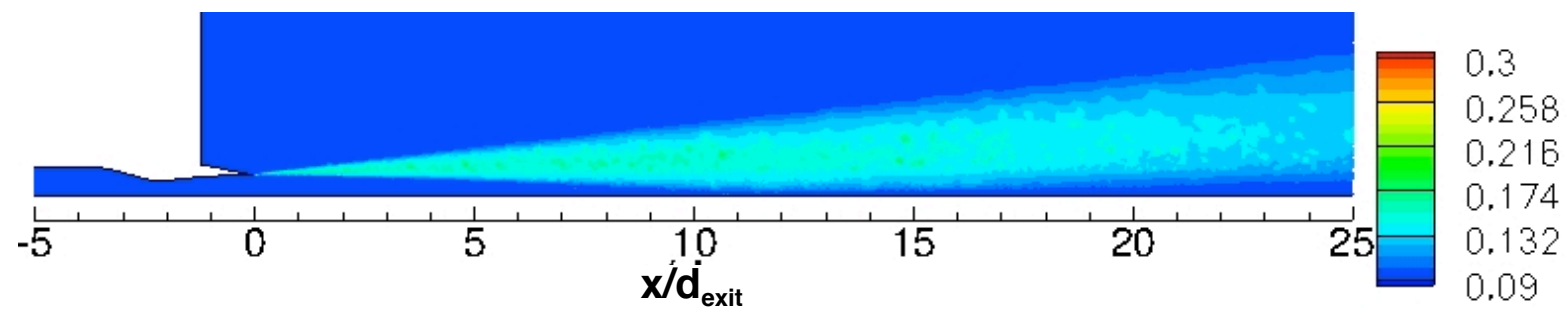

(b) $\mathrm{C}_{\mu}{ }^{*}$

Figure 7. Contours of Seiner nozzle's computed solution variables on the symmetry plane for nozzle plenum stagnation temperature of $2009^{\circ} \mathrm{R}$. 


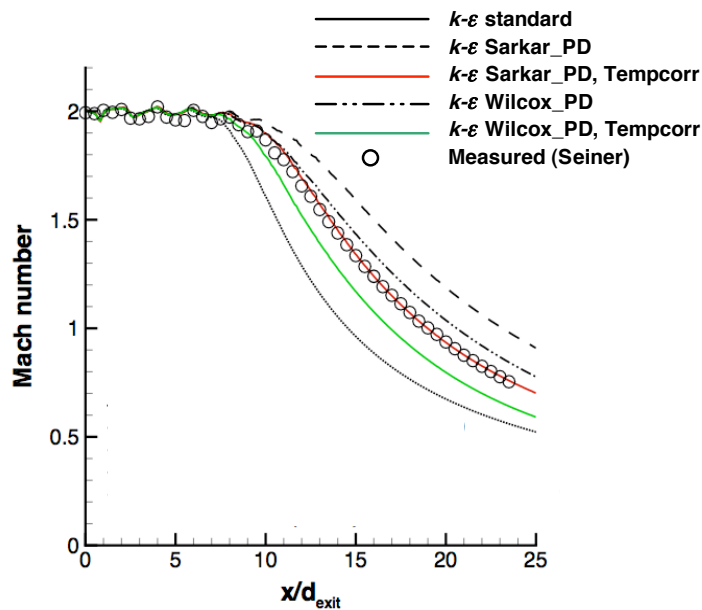

(a) Mach number

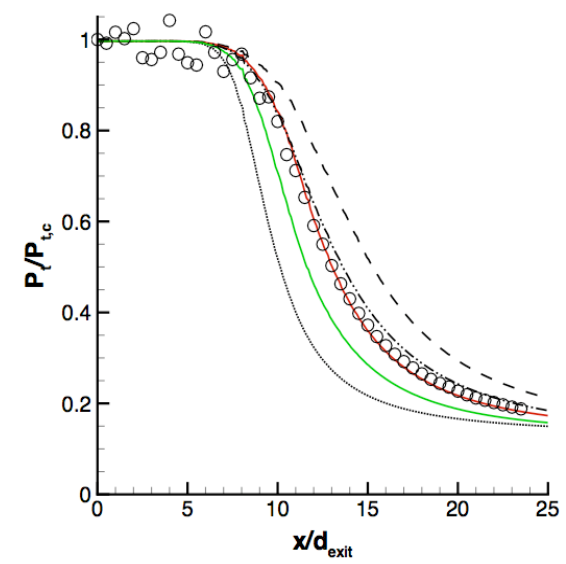

(b) Stagnation pressure ratio, $\mathbf{P}_{t} / \mathbf{P}_{t, c}$

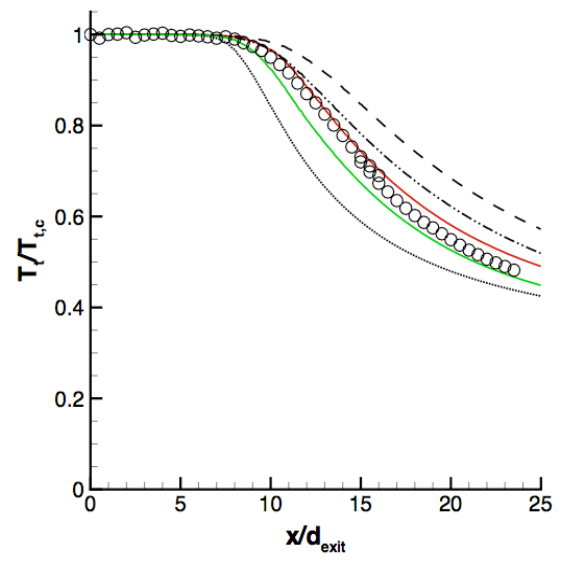

(c) Stagnation temperature ratio, $T_{t} / T_{t, c}$

Figure 8. Comparison of Seiner nozzle's computed and measured centerline profiles for nozzle plenum stagnation temperature of $2009^{\circ} \mathrm{R}$.

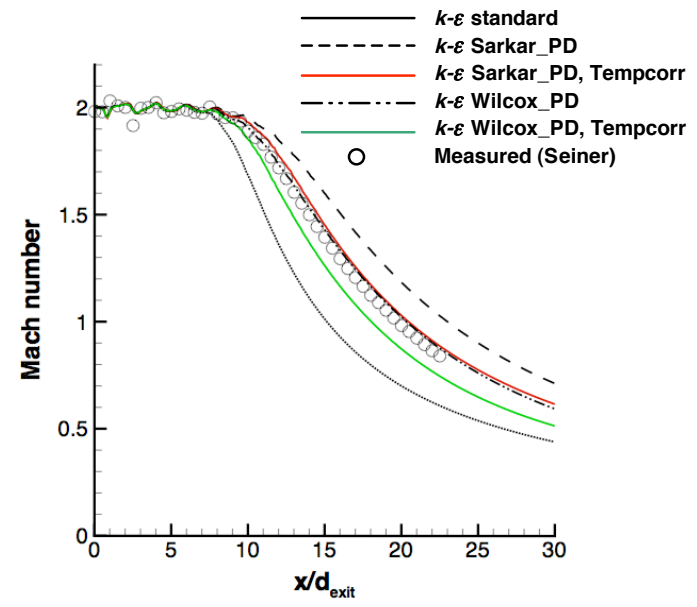

(a) Mach number

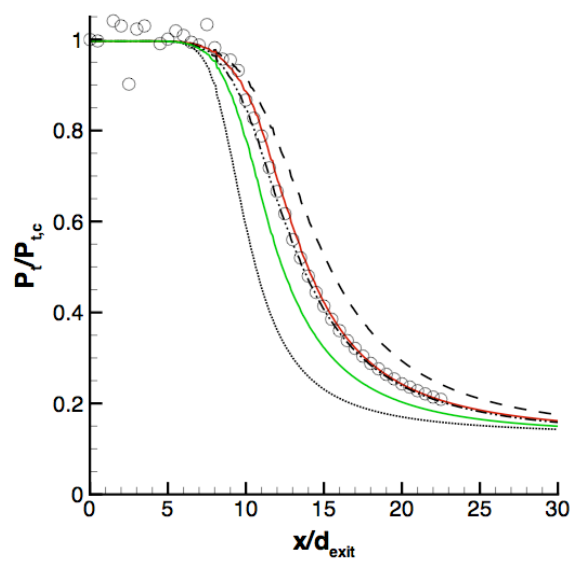

(b) Stagnation pressure ratio, $\mathbf{P}_{t} / \mathbf{P}_{t, c}$

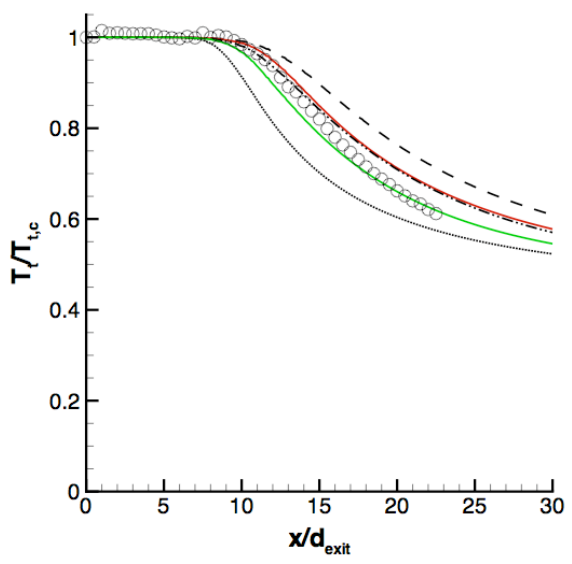

(c) Stagnation temperature ratio, $T_{t} / T_{t, c}$

Figure 9. Comparison of Seiner nozzle's computed and measured centerline profiles for nozzle plenum stagnation temperature of $1359^{\circ} \mathrm{R}$. 